\title{
The Role of Diet Therapy in the Patients treatment with Hyperuricemia and Metabolic Syndrome
}

\author{
Gapparova KM${ }^{1 *}$ and Yu G Chekhonina ${ }^{1,2}$ \\ ${ }^{1}$ Federal Research Centre of Nutrition, Biotechnology and Food Safety, Russia
}

${ }^{2}$ NI Pirogov Russian National Research Medical University, Russia

*Corresponding author: Gapparova KM, Federal Research Centre of Nutrition, Biotechnology and Food Safety, Moscow, Russian Federation, Russia

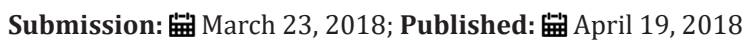

\section{Introduction}

There is no doubt about the importance of the amount of protein in the diet of obese patients. Adequate protein content in the hypo-caloric diet helps maintain muscle mass and reduce hunger. At the same time, the most common comorbid condition in obesity is hyperuricemia. At present, according to the results of numerous studies, hyperuricemia (GI) can really be considered as an independent risk factor for cardiovascular complications; it is directly related to other metabolic risk factors and is an important component of metabolic syndrome. In general, the correlation analysis demonstrates that the uric acid values correlate with almost all metabolic syndrome components, which may indicate the pathogenic role of uric acid in the development of this metabolic disorder [1-3]. According with the foregoing, the issue of not only quantitative but also qualitative composition of protein in the diet, as purine-containing products, which in turn affects the fluctuations in the level of uric acid in the blood serum, is topical. In addition, in the process of reducing body weight in patients with obesity, especially morbid, there is often an increase in the level of uric acid, which is the result of active catabolism of muscle mass. All this is a prerequisite for creating modified diets for patients with metabolic syndrome including hyperuricemia.

Patients and Methods of Research

Table 1: Characteristics of groups $(\mathrm{M} \pm \mathrm{m})$.

\begin{tabular}{|c|c|c|}
\hline \multirow{2}{*}{ Index } & Main Group & Comparison Group \\
\cline { 2 - 3 } & $\mathbf{n}=\mathbf{2 2}$ & $\mathbf{n = 1 8}$ \\
\hline Body mass, kg & $105,8 \pm 5,3$ & $107,2 \pm 6,7$ \\
\hline BMI, kg/m² & $35,9 \pm 2,1$ & $36,1 \pm 2,2$ \\
\hline WHR & $0,91 \pm 0,16$ & $0,92 \pm 0,14$ \\
\hline Body fat mass, kg & $48,6 \pm 4,72$ & $49,1 \pm 3,68$ \\
\hline Active cell mass, kg & $31,9 \pm 3,48$ & $32,6 \pm 2,91$ \\
\hline
\end{tabular}

\begin{tabular}{|c|c|c|}
\hline Total body water, $\mathrm{l}$ & $40,7 \pm 4,98$ & $42,6 \pm 5,01$ \\
\hline $\begin{array}{c}\text { Level of uric acid in the blood, } \\
\text { mkmol/l }\end{array}$ & $429 \pm 38$ & $438 \pm 40,3$ \\
\hline
\end{tabular}

Forty patients with obesity aged 18 to 67 were examined, of which $30 \%$ men and $70 \%$ women who were being treated at the FGBON Clinic FITs for Nutrition and Biotechnology. During the study, patients were divided into 2 groups. The main group included 22 patients with hyperuricemia, 18 were included in the comparison group. All patients had elevated levels of uric acid. Patients, taking allopurinol, were excluded from the research [46]. The symptom-complex of concomitant diseases corresponded to the metabolic syndrome Table 1.

All patients underwent physical examination and anthropometric measurements (body weight, WHR, BMI). The parameters of nutritional status were assessed: body composition by bioimpedanceometry, resting energy consumption by indirect calorimetry with determination of the oxidation rate of the main macronutrients, clinical and biochemical parameters of blood serum. During the research, the patients of the main group received a modified hypocaloric diet for 2 weeks. The protein part of the ration was modified by qualitative and quantitative composition by including a protein mixture, which contributed to a decrease in the quota of animal protein in the diet. The amount of protein in the diet correlated with the rates of oxidation by indirect calorimetry $[7,8]$. During the diet therapy, the patients of the main group had a less pronounced loss of muscle mass than in the comparison group, which is confirmed by the data on the evaluation of the body composition before and after the initiation of diet therapy. Biochemical blood tests showed a 12\% decrease in the level of uric acid from the initial value. In the comparison group, the level of uric acid tended to increase, which was $7 \%$ of the baseline values. A more pronounced decrease in insulin levels was registered in $16 \%$ in the main group. In the comparison group, this indicator was $11 \%$. Thus, the conducted study demonstrates the effectiveness of new approaches to the modification of diet therapy in patients with metabolic syndrome. 


\section{References}

1. Zakirova VB (2010) Metabolic syndrome, hyperuricemia and gout Practical Medicine 5(44): 27-31.

2. Barskova VG, Nasonova VA (2003) Gout and insulin resistance syndrome. Russian Medical Journal 23: 12-20.

3. Janashia PH, Didenko VA (2001) Is hyperuricemia a component of the metabolic syndrome? Russian Cardiology Journal 1(27): 29-34.

4. García Puig J, Angeles Martínez M (2008) Hyperurecemia, Gout and the metabolic syndrome. Curr Opin Rheumatol 20(2): 187-191.

5. Yang C, Yang S, Feng C, Zhang C, Xu W, et al. (2018) Associations of hyperuricemia and obesity with remission of nonalcoholic fatty liver disease among Chinese men: A retrospective cohort study. PLoS One 13(2): e0192396.

6. King C, Lanaspa MA, Jensen T, Tolan DR, Sánchez Lozada LG, et al. (2018) Uric Acid as a Cause of the Metabolic Syndrome. Contrib Nephrol 192: 88-102.

7. Marin M, Maalouf NM (2018) Effects of pharmacological reversal of hyperuricemia on features of the metabolic syndrome in patients with gouty arthritis. J Investig Med.

8. Wang P, Smith SE, Garg R, Lu F, Wohlfahrt A, et al. (2018) Identification of monosodium urate crystal deposits in patients with asymptomatic hyperuricemia using dual-energy CT. RMD Open 4(1): e000593.
Creative Commons Attribution 4.0

International License

For possible submissions Click Here

\section{Submit Article}

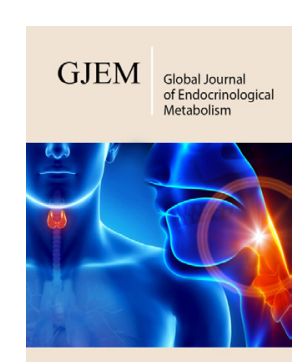

Global Journal of Endocrinological Metabolism

\section{Benefits of Publishing with us}

- High-level peer review and editorial services

- Freely accessible online immediately upon publication

- Authors retain the copyright to their work

- Licensing it under a Creative Commons license

- Visibility through different online platforms 